\title{
An analysis of the price escalation of non-linear water tariffs for domestic uses in Spain
}

\begin{abstract}
An efficient and sustainable use and management of water resources, especially in regions under water stress is increasingly required. The use of increasing block pricing involving an escalation or progressivity of unit prices in tariff systems is an economic instrument that contributes to their achievement. More progressive tariffs are expected to contribute to a better allocation of resources and avoid its wastage. This article analyses the determinants of the price escalation of water tariffs in Spain, a country subject to a high water stress in most of its territory. The main objective is to discern whether differences in the degree of progressivity in the tariffs are explained fully by climatic and scarcity factors or is, instead, unduly affected more by political and business criteria. Data from 967 municipalities are analysed using conditional mixed process (CMP) modelling. Among the results obtained about, tariff escalation is influenced by factors related to the environment in which the service is supplied and also by factors related to the decision makers' own strategic choices.
\end{abstract}

Keywords: Water tariffs; price escalation; progressivity; Spain; increasing block rates

\section{INTRODUCTION}

There are different topics of discussion surrounding the design and implementation of water pricing policies, both with regard to the price level itself and the design of the tariff. When it comes to the price level, one key consideration has to do with the need to enable a universal access to water. This issue is of particular concern in developing countries (UN Water, 2013, 2014) but it also affects disadvantaged groups in developed countries (García-Valiñas et al., 2010; Martins et al., 2013). Another concern is the requirement that prices suffice for recovering the cost of supplying the service (Hoque and Wichelns, 2013; Massarutto, 2007). Implementing this principle of cost-recovery would involve the elimination of subsidies to water users, so that water prices could appropriately signal water resource scarcity and promote practices consistent with the objective of efficiently allocating these resources, electoral opportunism strategies would be avoided, and consumption levels would fall closer to the users' real needs. 
The design of the structure of water tariffs has also been the subject of study (GarcíaValiñas, 2005; Rogers et al., 2002). The practice of applying binomial tariffs (including both a fixed and a variable component) is increasingly popular (Hernández-Sancho and Molinos-Senante, 2015; OECD, 2010). The fixed part of the tariff guarantees a level of revenue per user with which to cover the associated fixed costs of supplying the service, helping, therefore, to ensure cost recovery. The variable part of the tariff, most usually involving increasing block rates (IBRs), aims to ensure the sustainable and efficient use of water resources. With increasing block rates, unit water prices are progressively ${ }^{1}$ higher with increasing water consumption. This type of tariff aims in principle to prevent waste, mainly in high-income families, although if other measures are not applied, it penalizes larger households (Arbués and Barberán, 2012).

In essence, the choices involved in the design of a nonlinear water tariff include deciding whether a non-zero fixed fee will be used, deciding about its size and also whether it will entitle the user to any free water allowance, and if so, of what size; deciding how many blocks of consumption to use in the variable component of the tariff; and deciding which price to apply to each of the blocks. It is the combined effect of all these elements that results in a given degree of price escalation in the tariff and it is the combination of these elements that is, thus, supposed to drive the allocation of water resources to something closer to its most efficient.

Several recent studies have analysed the determinants of price levels for residential water uses (García-Valiñas et al., 2013; Ruester and Zschille, 2010). Some of these works found that differences in water prices among cities are due, in part, to differences in the costs of providing the service, due to the need to apply more complex water treatment techniques, the need to incur higher energy costs for resource extraction, or other similar reasons. However, there are other factors in principle unrelated to the costs of service, such as the ideology of the ruling party in the municipality, industry structure, or type ownership of the water supplier (Bel et al., 2015; Chong et al., 2006) that still seem to drive price differences. In these cases, citizens and taxpayers may perceive a certain degree of unfairness affecting access to a good that is necessary for life (Martínez-Espiñeira et al., 2012).

\footnotetext{
${ }^{1}$ As explained in Section 4.1, it is this kind of progressivity that we refer to throughout. That is, we are concerned with the degree of price escalation within the tariff. This should not be confused with the more common use of the term, which involves the notion that richer individuals pay more for something or are taxed proportionally more. We use progressivity and price escalation indistinctly in the paper.
} 
Other studies have focused instead on the choice of fixed components of the tariff and their effects in terms of efficiency and equity (Dandy et al., 1997; Martínez-Espiñeira, 2002).

We focus instead with the remaining element of the non-linear tariffs, so the objective of the present contribution is to analyse the determinants of the different degrees of price escalation (progressivity) built into the variable component of water tariffs for residential uses in Spain.

To be sure, the analysis of progressivity in taxation schemes has been a frequent topic of analysis. For example, there have been studies that address this issue in the analysis of local taxes (Bahl et al., 2002; Chernick, 2005; Foster, 2013). However, to our knowledge, there is only one previous example of this type of research in the context of water tariff, namely the analysis by Boyer et al. (2012), applied to four Southern US States, which discusses what factors influence the choice of the type of tariff structure (increasing block, uniform rate, or decreasing block). Our focus is in finding out whether more progressive tariffs are applied in areas with higher degrees of water stress, or whether differences in the progressivity of the rates are, instead, due to other reasons. The analysis is conducted using municipal data for Spain, a country where much of the land is under water stress. Our database contains information for 967 municipalities for the year 2014.

We propose a measure of local progressivity of the tariff structure based on the escalation of the average unit prices for seven levels of consumption. Within a simple least squares framework, we use a conditional mixed process approach to jointly model the value of this measure for each municipality and two other aspects of the tariff structure, namely the number of pricing blocks used and the size of the fixed component of the tariff. This joint modelling of these three variables accounts for the likely correlation among them and makes it possible to correct for endogeneity bias. Our main findings are that the degree of tariff escalation is influenced not only by factors related to the environment in which the service is supplied, such as the level of water scarcity in the municipality but also largely by other determinants related to the decision makers' own strategic choices.

The paper is organised as follows. After this introduction, Section 2 deals with the factors that may influence the degree of price escalation in the tariffs. In the third and fourth sections, the data and methodology employed in the analysis are described. In Section 5 , the results are shown and discussed, before a concluding section. 


\section{DETERMINANTS OF PRICE ESCALATION IN WATER TARIFFS}

The use of progressive tariff systems is justified on the grounds that water, being a good that satisfies different needs of the individual, can be viewed differently from an equity perspective, depending on the amount consumed. Thus, water for drinking and cooking is considered a basic necessity. On the other hand, water for watering gardens and filling swimming pools would often be considered a type of luxury good. Other uses fall in an intermediate category, for example, those related to laundry and household cleaning.

Within the first levels of consumption, it is agreed that water prices should not be a deterrent for families with low incomes. Water accessibility should be guaranteed, at least in amounts sufficient to cover basic needs. However, as consumption levels rise above the category of necessities, the unit price of water increases in consumption blocks. Higher water consumption levels are penalized, which is expected to contribute to achieving the objectives of efficiency and sustainability of water resources. Therefore, the variable part of the tariff is supposed to take into account objectives of accessibility, efficiency and sustainability.

In Spain there exists an extraordinary diversity of tariff systems. This is because water prices are set at the municipal level, as each municipality has jurisdiction over the management of the water service in the municipality. ${ }^{2}$ This great variety of tariff systems in a country with 8,119 municipalities leads us to consider what factors may explain the differences in the degree of progressivity embodied in the tariff.

We consider in our analysis, first, determinants of relative scarcity or abundance of water resources in each municipality. From the perspective of economic and environmental rationality, the use of a tariff structure that encourages a more efficient and sustainable water use would be expected in geographic areas with lower rainfall and higher temperatures, since they face more water scarcity, (Bjornlund and Rossini, 2005; Martinez-Espiñeira et al., 2012).

First hypothesis: Increased water stress is associated with more progressive water tariffs. In areas with more water stress, we expect to observe a stronger penalty on higher levels of consumption.

\footnotetext{
${ }^{2}$ Except for the cases in which tariff design is conducted in larger areas when municipalities decide to form associations or consortia and the water service is supplied by a single management unit.
} 
The socio-economic setting in which the service is supplied can also affect the decisions made about the tariff. The average level of income in the jurisdiction may be a relevant factor. At a first glance, one might expect that in richer cities it will be easier to apply more progressive tariffs. This is because the impact of the penalizing prices attached to the higher consumption blocks will be less noticeable the richer the households facing them. However, several studies relate higher income with lower tax rates and lower progressivity in tax systems (Chernick, 1992; Fletcher and Murray, 2008) or they find that these are not affected by income (Chernick, 2005). The rationale behind this stems from the fact that citizens will not normally support those policies that go against their personal interests. Therefore, in towns with higher income, it is to be expected that the political cost derived from the adoption of a more progressive tariff structure will be higher, so the expected effect of income on the degree of tariff progressivity is in principle ambiguous.

Second hypothesis: A higher income is associated with higher degrees of progressivity in the tariff.

Also linked to the environment in which the service is provided would be the effect of the seasonality in the demand related to the effects of tourism. In Spain most of the tourism is linked in one way or another to water use. Filling pools, watering gardens and resort developments, or irrigation of golf courses are obvious examples. One would expect that in cities that receive a greater influx of tourists local governments choose to penalize more sharply the use of water-related recreational activities.

Third hypothesis: Increased tourist activity is associated with more progressive water tariffs.

In order to explain the observed differences in the progressivity of water rates, one must also take into account political and ideological factors (OECD, 2003). In terms of ideological orientation, left-wing parties are expected to be more committed to social and environmental causes and, therefore, more likely to adopt more progressive rates. They will likely be more prone to setting lower prices for the lowest levels of consumption, which facilitates access to the resource for the household with the lowest incomes. At the same time, they might more likely penalize luxury consumptive uses. In fact, there is some evidence to support the notion that left-wing parties tend to set more progressive taxes. (Chernick, 2005; Fletcher and Murray, 2008)

Fourth hypothesis left-wing parties tend to apply more progressive rates. 
Political parties more often than not try to avoid implementing unpopular measures, such as an increase in taxes or in prices (Jacobs and Howe, 2005). In this sense, one can expect more stable governments to adopt more politically-risky measures. Thus, the increase in water rates for higher consumption blocks aimed at penalizing resource waste and promoting efficiency might be unpopular for higher income families. A greater degree of security and stability enjoyed by the municipal government makes it easier to make unpopular decisions. Some evidence of this phenomenon has been found with relation to taxes (Fletcher and Murray, 2008; Solé-Ollé, 2003).

Fifth hypothesis: more stable local governments are associated with higher degrees of progressivity in water tariffs.

As a further possible cause of heterogeneity in the progressivity of water rates in Spain, we should consider the differences in the type of ownership of the water utility. Spanish law estipulates that the municipality is responsible for the management of water service to its citizens, but the local government has the authority to outsource the management to private companies and public-private enterprises management.

In response to political interests, one might expect different behaviour between public and private ownership of the water supplier (Martínez-Espiñeira et al., 2012). When the management of the water supplier is public, citizens more easily relate a rise in the price of water within higher consumption blocks with a decision made by the local government. When ownership is private, local governments can always blame the decision on the private managers. Thus, local governments would expect a weaker impact on their political image when the rise in water bills occurs while the management of the water utility is in private hands.

In terms of business strategy, a sharper escalation in the water rates should be expected when the water supplier is a private firm. Higher levels of consumption are supposed to correspond to higher levels of household income. As predicted by models of water demand, the price elasticity of demand is less than one (Arbués et al., 2003; Worthington and Hoffman, 2008). This implies that increases in the price of water lead to proportionately smaller reductions in consumption, which will result in higher revenues for private enterprise.

Sixth hypothesis: When management of the water supply is private, water rates are more progressive. 


\section{DATA}

The database consists of information obtained for 967 Spanish municipalities, aimed to be used with reference to the year 2014. The sample captures $11.91 \%$ of the country's municipalities and covers $48.58 \%$ of the total Spanish population.

The first step in the data collection exercise involved obtaining information about the water tariffs in each municipality. This process required an exhaustive perusal of the official notes about water prices published in the official gazettes of the different provinces and autonomous communities in Spain. It should be noted that this procedure might have resulted in a possible selection bias, as it is typically the largest municipalities that tend to revise their water rates with greater frequency and, therefore, it is easier to find information about these municipalities. In any case, as shown in Table 1, plenty of information was obtained also about smaller municipalities.

\section{*** Table 1 about here ${ }^{* \star *}$}

Next, information about variables that might explain differences in the progressivity of the tariff structures was added to the database. The percentage of occupancy of reservoirs in the relevant river basin (OCCUP), average temperatures (TEMP) and rainfall (PLUV) were included as proxies for levels of water stress. We also included a set of variables reflecting the socieconomic characteristics of each municipality, namely population density (DENSITY), a variable measuring economic activity (ECON) that was used as a proxy for income in the municipality, a proxy for tourism activity (TOURISM), and the unemployment rate (UNEMP).

In order to capture the influence of ideological factors on the pricing choices, we used several variables representing the ideology of the local governments. Spain's Partido Popular (PP) represents the centre-right, the Partido Socialista Obrero Español (PSOE) represents the centre-left and Izquierda Unida (IU) is a party falling further to the left than PSOE. These three parties have a national representation in Spain but there exist many other smaller parties with a more regional character. These latter parties were grouped into two variables. LEFT represents left-wing regional parties and RIGHT their right-wing counterparts. Further political variables were included. STAB is a proxy for the stability over time of local government and MAJOR is a proxy for the degree of public support of the local government elections. Additionally, we added a 
binary indicator for each of the 18 autonomous communities (Comunidades Autónomas) in Spain, which we labelled CCAA. ${ }^{3}$

In order to control for the management style of the water supplier in the municipality, we included a proxy for the type of ownership of the water utility serving the municipality (OWNERSHIP) and a variable indicating whether the municipality belongs to a supramunicipal service unit (CONSORTIUM). Finally, we also considered two variables to describe the water tariff: the amount of the fixed component of the tariff (FIXED) and the number of blocks included in the variable part of the tariff (BLOCKS). Appendix 1 provides a detailed description of these variables and their source. Table 2 contains selected descriptive statistics.

*** Table 2 about here ***

\section{Methodology}

\subsection{Measuring tariff progressivity}

Several previous works have addressed the analysis of factors behind the choice of a particular rate/tariff structure, mainly comparing the choice among increasing block, decreasing block, and uniform tariffs (Boyer et al., 2012) or examined the determinants of the degree of effectiveness of increasing block rate (IBR) tariffs (e.g. Madhoo, 2009). However, as far as we know, no previous studies have examined the determinants of the degree of progressivity (or price escalation) in water tariffs. There is, however, a small body of research examining the determinants of progressivity in taxes (Bahl et al., 2002; Bucciol et al., 2013; Chernick, 1992, 2005; Egger et al., 2014; Fletcher and Murray, 2008; Foster, 2013; Padovano and Turati, 2012) or benefits systems (Orr, 1976).

With respect to the methodology employed, the first modern measure of progressivity was developed by Musgrave and Thin (1948) for the personal income tax. ${ }^{4}$ After this seminal contribution, numerous indexes have been proposed to address this social concern, mostly related to tax systems. These indexes are normally divided into three main categories: local, global, and uniform (Seidl et al., 2013). The main difference among them is that local measures of tax progressivity focus exclusively on the

${ }^{3}$ In our analysis, the eighteenth community, Valencia, was omitted from the set of independent variables and thus treated as the benchmark for the estimated effects of the rest of such indicators.

${ }^{4}$ Consisting mainly of comparing ex ante and ex post Gini coefficients of income. 
structure of the tax, while global and uniform measures try to incorporate considerations regarding income distribution.

Most of the previously mentioned literature on the determinants of progressivity relies on global measures of progressivity and only one study focuses on the study of tax structures themselves (Fletcher and Murray, 2008). Given that we do not intend to account for the effects of tariff structure in terms of income redistribution but only in terms of the structure of the water tariffs, measures similar to the local tax progressivity indexes is deemed to be the most appropriate.

As noted in Section 2, in Spain there is a great diversity of tariff systems, since water prices are set at the municipal level, except for those cases in which individual municipalities form groups to take advantage of economies of scale. In Spain, water tariffs have usually two components, a fixed portion charged to the user just for being connected to the public water network and a variable component, usually with increasing rates according to consumption blocks. As a first step in the analysis of the progressivity of the tariffs, we calculated the total variable (that is excluding any fixed component of the tariff) cost of purchasing several hypothetical monthly amounts of water: namely $3,5,10,15,20,25$ and 50 cubic metres. This particular choice of consumption amounts follows Martínez-Espiñeira et al. (2012), who noted that the average water monthly use in Spain is about $15 \mathrm{~m}^{3}$ household per month and considered three additional amounts around that benchmark (three larger and three smaller). Table 3 shows the main descriptive statistics related to these variables.

*** Table 3 about here ${ }^{* * *}$

Intuitively, by progressivity in water tariffs we understand that, as consumption increases, so does the average price. Hence, in order to measure progressivity, we developed the following index. We added up, for each municipality, the difference between the average unit price (the price per cubic metre) resulting from the expected bill corresponding to 5 cubic metres of consumption per month and the corresponding average price for 3 cubic metres, together with the subsequent differences until reaching the difference in unit prices between 50 and 25 cubic metres. This summation was then normalized dividing by the average price of 25 cubic metres. Therefore, our measure indicated the degree of price escalation in each tariff, without a higher level of general prices in a municipality unduly influencing the value of the resulting variable. Mathematically, the calculation of the progressivity indicator can be shown as: 


$$
P R O G=\frac{\sum_{w=5}^{50}\left(\frac{\text { ill }_{w}}{w}-\frac{\text { bill }_{w-1}}{w-1}\right)}{\frac{\text { bill }_{25}}{25}} ; \text { for } w=3 \mathrm{~m}^{3}, 5 \mathrm{~m}^{3}, 10 \mathrm{~m}^{3}, 15 \mathrm{~m}^{3}, 20 \mathrm{~m}^{3}, 25 \mathrm{~m}^{3}, 50 \mathrm{~m}^{3}
$$

It should be stressed that this measure of progressivity may be related to the notion of progressivity based on the idea that richer individuals pay proportionally more for the service (that is, they pay higher average water prices) but only if it is acceptable to assume that households with higher incomes tend to consume larger amounts of water. Since this is not necessarily the case, we must reiterate that our measure of progressivity is merely a measure of the escalation of prices built into the tariff.

According to Kakwani (1977), tax progression can be defined as the departure from proportionality of a tax system. Our measure of progressivity intends precisely to reflect this concept by measuring the degree of deviation from proportionality in water tariffs. Therefore, flat rate tariffs, which implicitly lead to average prices that are decreasing in consumption, and tariffs based on decreasing block rates (DBRs), which explicitly do so, would result in a negative value of our measure (PROG), signalling that these pricing policies are indeed regressive on consumption. In the case of volumetric proportional rates, those for which a fixed amount is paid for each cubic metre of water, the value yielded by our measure will be equal to zero, as the average price does not vary among levels of consumptions, and for those IBRs (Increasing block rates) the index obtained will be positive and its size will increase with the degree of price escalation in the tariff.

\subsection{Econometric Analysis}

In order to account for the likely endogeneity among the dependent variable of interest $P R O G$ and two of the main drivers of the tariff structure that ultimately determine its value (BLOCKS and FIXED) we modelled them jointly as a system of three equations. We used, to this end, conditional mixed process (CMP) modelling, which is a highly flexible way to approach a joint equation specification, using Stata's (Statacorp, 2011) CMP routine (developed primarily by Roodman, 2011). This approach relies on a simulated maximum likelihood method for evaluating multivariate normal distribution functions based on the Geweke-Hajivassiliou-Keane (GHK) algorithm (Börsch-Supan, et al., 1992; Börsch-Supan and Hajivassiliou, 1993; Hajivassiliou and Ruud, 1994; Keane, 1994). ${ }^{5}$

\footnotetext{
${ }^{5}$ The GHK simulator exploits the fact that a multivariate normaldistribution function can be
} expressed as the product of sequentially conditioned univariate normal distribution functions, 
Approaching the estimation as a system of equations we used makes it possible to account for unobservable municipal' characteristics (cross-sectional effects) or circumstances (temporal effects) that may impact two or more of the dependent variables considered. This system estimation will improve the efficiency of the whole set of estimates if there is indeed correlation among the error terms of the equations in the system. ${ }^{6}$

The true power of the CMP model is given by the various systems of equations it admits. Indeed, two-stage least squares (2SLS), IV-Tobit, IV-probit, probit with Heckman selection, IV ordered probit, and any combination of these systems can all be modelled under the CMP framework. However, although the flexibility of the CMP specification could be exploited further (for example by treating the number of blocks as an ordered dependent variable rather than a continuous one), ${ }^{7}$ because of the wide range of models that are nested within it, we chose to simply treat all dependent variables as continuous and use a system of joint classical OLS regressions.

The three equations were simultaneously estimated under the assumption that they represent a recursive process but not a full one: the municipality's level of tariff progressivity captured by PROG is affected, largely by construction, by the size of the fixed quota and by the number of blocks in the tariff, the only other determinant being the relative differences between the prices in different subsequent price blocks. However, the converse does not apply. That is, we considered that neither the choice of the number of blocks included in the tariff structure nor the size of the fixed quota were affected by the degree of progressivity.

Our joint modelling of the three equations allowed for the error terms to be correlated across equations and thus for any endogeneity in the modelled equations to be

which can be easily and accurately evaluated (Cappellari and Jenkins, 2003). Further details about this technique can be found in Train (2003) or Greene (2003, 931-933) and references therein.

\footnotetext{
${ }^{6}$ An alternative approach to correct for endogeneity would involve the use of the instrumental variables (IV) method, a very common approach (Cameron and Trivedi 2009, p. 177). Although more efficient computationally, some issues with this multi-stage method are that an endogenous regressor may lack strong or valid instruments. Furthermore, inherent in the IV method is the loss of information, specifically the component of the endogenous regressor $X$ that is correlated with the error $\varepsilon$ along with any information in $X$ that is not correlated with the vector of instruments Z. In CMP, this loss of information does not apply, since the endogeneity is corrected by way of the error correlation estimates, leading to a more statistically efficient estimation. Additionally, CMP does not rely on the ability to justify the untestable prior of instrument validity.

${ }^{7}$ Ideally we would have liked to model it as a count. However, this option is, to our knowledge, not available within the CMP framework in Stata (see Roodman, 2011).
} 
corrected. The null hypothesis of exogeneity (zero correlation) can be tested. In particular, the error correlations were estimated by the coefficient $\rho_{i j}, i, j=1,2,3$, the significance of which provides evidence supporting endogeneity. A positive and significant estimated of $\rho_{\mathrm{ij}}$ implies that common omitted factors tend to increase or decrease both errors. A negative correlation between two regression errors suggests instead that an omitted common factor will tend to increase the error of one and decrease the estimate of the other or vice versa.

\section{RESULTS}

Table 4 shows the results of two types of estimation. The first type, shown in the first three columns of the table, is a basic least squares analysis of the progressivity index (PROG), the number of blocks in the tariff (BLOCKS), and the size of its fixed component (FIXED), using three separate independent regressions, denoted by OLS. The last three columns of the table show the equivalent components of a joint regression of these three dependent variables using the CMP routine in Stata, described in the previous section.

The results show little difference between the joint and the independent analysis in the case of the regressions on the two features of the tariff (BLOCKS and FIXED). The differences between the model that accounts for endogeneity by allowing a correlation among the regression errors results only in almost imperceptible changes in standard errors and, consequently, the associated levels of significance of the individual estimates.

However, the main regression of interest for our purposes (the one which models PROG) is more substantially affected by the correction for the endogeneity of BLOCKS and FIXED, not only in terms of the significance of the estimates but also in terms of their size. As expected, however, the main effects of the correction for endogeneity affect the two variables whose effects were suspected to be estimated with bias. The effect of FIXED appeared to be underestimated by the independent OLS regression, while it exaggerated the effect of BLOCKS, which is not even significantly different from zero when the regressions are run jointly.

The results in terms of the estimated coefficients of correlation between regression errors further confirm the endogeneity of both BLOCKS and FIXED in the main 
regression of PROG. ${ }^{8}$ Both $\rho_{12}$ and $\rho_{13}$ are indeed highly significant. As expected, the former suggests that factors unaccounted for in the regressions for BLOCKS and PROG have a positive correlation. That is, unobserved variables that tend to make the tariff complex tend to make it also progressive and vice versa. In even simpler terms, in a context of increasing block pricing schemes, the reason why tariffs have blocks in the first place is that the tariff designer intended to embed progressivity into the tariff. Although there are other more relevant elements to tariff progressivity than its complexity in terms of the number of blocks (namely the size of a fixed component if any and the actual differences between adjacent blocks), we should clearly expect a positive link between tariff complexity and progressivity in a municipality. However, once we account for that endogeneity, and again, as expected, we can see that tariff complexity by itself does not seem to significantly affect the degree of progressivity. It is not a significant predictor of its size. Again, it is the size of the fixed component, as our results also confirm, and, more directly, the price differences between blocks that determine the degree of progressivity.

Conversely, there seems to be a negative association between the error in the PROG equation and the error in the FIXED equation. Not surprisingly, unobserved factors leading to a large fixed component in the tariff correlate in a negative way with unobserved factors that tend to be present when the degree of progressivity is strong. Since our formula to measure progressivity is based on the analysis of the differentials between average prices for different levels of consumption calculated only on the basis of the variable component of the tariff, it is, however, not surprising that the effect of variable FIXED on PROG is positive. This is in part because of the effect of the relatively frequent cases in which the FIXED component of the tariff entitles the user to a free minimum allowance including a certain number of cubic metres. In those cases, we should expect, by construction, substantial price escalation between the first average water prices included in the price escalation formula since the very first ones will be equal to zero (the average variable price of water within the free allowance). Additionally, it is possible that the tariff designers who include a relatively large fixed component in a tariff choose to compensate for its regressiveness by including a higher degree of price escalation in the upper levels of consumption. Since cost recovery is more easily guaranteed in those municipalities, they can afford to set relatively low prices for low consumption blocks without jeopardizing revenue stability for the utility. This explains how overall, the tariff ends up with a higher degree of price escalation.

\footnotetext{
${ }^{8}$ As explained in Section 4.1, the model is not fully recursive, since BLOCKS and FIXED enter the equation explaining PROG but the reverse does not apply.
} 
Finally, it is interesting to note that, although the correlation between PROG and FIXED and $P R O G$ and BLOCKS is strongly significant, there is no unaccounted for correlation between the errors of the regression of BLOCKS and the one of FIXED. These two regressions, although not the main interest of our study, could be consistently estimated separately, so, in fact, it makes no qualitative difference whether we look at the results from the second and third columns or at the fifth and sixth columns of Table 4.

It is noteworthy that our OLS regressions manage to explain a relatively large proportion of the variability of the dependent variables using cross-sectional data. As shown by the coefficients of determination, in all three cases over $50 \%$ of the variance of the dependent variable is explained by the model.

*** Table 4 about here ${ }^{* * *}$

Among the set of variables proxying water stress, only PLUV is significant and has the expected sign. A lower abundance of rainfall is associated with more progressive tariffs. In addition, we find that the smaller the volume of rainfall the higher the fixed part of the tariff and the more blocks there are in its variable component. We recall that most of Spain is subject to water stress. The 2004/2005 hydrological season was unusually dry in Spain. In 2005 many Spanish municipalities adopted exceptional conservation measures, such as banning watering public parks and private gardens, street cleaning, except in cases of strict need for public health reasons, filling public and private pools, and the washing of cars, as well as banning the operation of public water fountains or refrigeration systems without a closed circuit. Some municipalities added financial penalties for infringement to these measures. In short, the problem of lack of rain in some areas is of such importance that it is reasonable for these municipalities to adopt tariffs that tend to penalize the use of water resources for medium and large levels of consumption.

Among the variables that provide information on various characteristics of the municipality, DENSITY appears to exert a significant effect. The ability to obtain higher revenues in more densely populated areas, where one would also expect lower average costs due to economies of scale and density, may explain the sign of DENSITY. In some cities in Spain, mainly in coastal areas that attract those demanding "sun and beach" tourism and interior cities with rich historical and cultural heritage, there are important peaks and troughs of demand. In these cities the fixed part of the tariff is higher, likely because in order to meet the peak demands, it is necessary to 
maintain excess capacity at other times, so average fixed costs will be higher in those municipalities.

Finally, the results suggest that in those municipalities with more economic activity, the fixed part of the tariff is lower. This result could be due to political and business interests. In a country like Spain, where many families with middle and high incomes have a second residence, it might not be in the municipality's interest to fix high sevice connection fee and overtax water uses. It should be borne in mind that the model of economic growth in Spain during the 1990s and 2000s was precisely based on the construction of these residential areas. A substantial share of municipal revenues in many cities was associated with this growth model.

Regarding the variables related to the style of service management, PRIVATE presents the expected sign but is not significant. Moreover, we find that PRIVATE is positively and significantly related to the number of blocks of the tariff. Privately managed utilities might be both more interested in and more capable of exploiting the use of complex rate designs that can generate higher profits by introducing elements of price discrimination based on enhanced information about the price-responsiveness of users within different consumption blocks. CONSORTIUM is positively related to the progressivity of the rates. This may be because this variable is capturing the professionalization of the water service, especially in small towns, which might otherwise choose to apply somewhat less sophisticated tariff designs. Supramunicipal associations are usually encouraged in the case of small-sized municipalities with a low quality water supply service that cannot easily cope with the costs of providing the service. By partnering with other municipalities, they can exploit economies of scale and delegate management services to public and private companies, introducing in the process improvements in the management of the service, in this case designing tariffs with greater progressivity.

When it comes to the set of political variables, we can highlight the results obtained for the proxies of ideology of municipal governments. In terms of national parties, in those municipalities where the PSOE (centre-left), IU (left) and left-regional parties have ruled for at least 8 consecutive years, ideology is not a relevant factor in explaining differences in the progressivity of the rates. The absence of significant differences in price escalation between left and right-wing parties may well seem counterintuitive. However, it might not be surprising if we consider that even some evidence have been found in previous research relating right-wing parties with more progressive taxes and benefits (Padovano and Turati, 2012; Bucciol et al., 2013). One possible explanation 
for this type of results is that when the right-wing rules the municipality, the pressure by the left-wing parties in opposition may, paradoxically, prompt the more conservative public administrators to adopt pricing policies similar to the ones embraced by the opposition. In fact, water pricing is an issue under close surveillance by citizens. In this regard, consumer organizations are very sensivite to changes in water tariffs and they publish rankings in which differences in water policies among the main Spanish cities are highlighted (FACUA, 2013; OCU, 2014).

Furthermore, a significant and negative relationship is detected between STAB and price escalation levels. This could be due to the fact that longer-ruling government officials become complacent and fail to apply the necessary policy changes, such as the introduction of more complex and potentially less popular water tariffs. It is also possible that our estimate is actually capturing a reverse causality; staying in power longer might be the consequence of following a strategy based on the maintenance of continuist policies. Moreover, MAJOR is not significant, suggesting that it makes no difference whether the local government rules with a majority or not.

Finally, many of the CCAA dummies do capture regional differences, which may be due, at least in part, to long term differences in regulatory and institutional frameworks.

\section{Discussion AND Conclusion}

The design of water tariffs can help meet economic and environmental goals. The use of increasing block tariffs results in an escalation or progressivity in the price per unit which aims at simultaneous objectives of efficiency and environmental sustainability. Several studies have examined the impact of the design of increasing block tariffs on their effectiveness at achieving these goals. However, to date no studies have analyzed the factors that influence the choice about the degree of progressivity embedded in the tariff structure. This is important, since the setting in which decisions about water rates are made can influence the rate design itself. This means that different scenarios are comparatively more likely to result in more progressive rates and, therefore, more likely to achieve the aforementioned objectives of a pricing policy.

We can categorize the set of factors that may influence tariff design in two main groups. A first group would include environmental factors. In the second block we would find factors related to the decision maker's own strategic choices. Our results, in line with our expectations, suggest that in areas facing higher degrees of water 
scarcity, the rates tend to be more progressive. Additionally, other factors beyond the decision-maker's control that have to do with the decision making environment tend to affect the tariff design. We find that population density influences the degree of price escalation in the tariff, and that the fixed part of the tariff is influenced by seasonality of demand and economic activity.

Among the factors associated with the political allegiances of the decision maker, we found that the length of time in office of the ruling municipal party, and the decision to form a supramunicipal consortium affect the degree of price escalation in the tariff. In view of the results obtained, the question arises as to whether the progressivity built into the water rate design, should depend on factors other than the environmental ones. It seems reasonable that citizens be allowed to participate in the decision about the degree of progressivity in the tariff. In Spain this participation right can be indirectly exercised every four years by voting in the municipal elections for the party that better represents one's ideological preferences in this and other matters. Leaving aside the fact that the ideology of the local government does not affect the chosen degree of block price escalation in the expected direction in our sample, one should wonder whether the administrative level to channel citizen preferences on this issue is the appropriate one. Making decisions at the municipal level that can affect a much wider area, as is the watershed, is unreasonable. Individually designing tariffs to promote an efficient and sustainable use of the water resources will be of limited use if the surrounding municipalities that share the same catchment fail to also choose pricing schemes with similar aims.

The main policy recommendation that can be drawn from our results is that in Spain standards and controls should be established at least at the watershed level to regulate the design of water rates for residential uses. The standardising of the different aspects of pricing policy would make it possible for all the citizens in the same water basin to make decisions about their water consumption based on shared conditions. Thus, the responsibility for and effort needed to achieve an efficient and sustainable allocation of water would be shared more equitably among citizens.

This study, to our knowledge, is the first to analyze the determinants of progressivity of water rates for residential uses. We found several useful results but it would be necessary to further this line of research in order to gain a fuller understanding of which factors end up determining the degree of price escalation in nonlinear water tariffs. An obvious extension of this work would consist of analyzing the determinants of the progressivity of tariffs in other geographical areas that lack a regulatory framework 
overseeing tariff design control. In countries where there are supra-municipal regulations and controls in place, the level of analysis could be changed, analyzing the differences between watersheds instead of municipalities. This exercise would further help understand the differences in the strategy used by policy makers at the basin level to make efficient and sustainable use of the water resource.

Finally, since we only used a single index of progressivity, it would also be interesting to consider conducting the same analysis based on alternative measures of the progressivity in the tariff. For example, it is quite possible that different factors affect the degree of progressivity differently, so it would be of interest to compare the differences in progressivity when measured considering only the lowest levels of consumption or when considering only the highest levels of consumption. 


\section{REFERENCES}

Arbués, F., García-Valiñas, M. A., Martínez-Espiñeira, R. 2003. Estimation of residential water demand: a state of the art review. Journal of Socio-Economics 32(1), 81-102.

Arbués, F., Barberán, R., 2012. Tariffs for urban water services in Spain: household size and equity. International Journal of Water Resources Development, 28(1), 123-140.

Bel, G., González-Gómez, F., Picazo-Tadeo, A.J., 2015. Does market concentration affect prices in the urban water industry?. Environment and Planning C: Government and Policy. In Press.

Bjornlund, H., Rossini, P., 2005. Fundamentals determining prices and activities in the market for water allocation. International Journal of Water Resources Development, 21(2), 355-369.

Bahl, R., Martinez-Vazquez, J., Wallace, S., 2002. State and local government choices in fiscal redistribution. National Tax Journal 55(4), 723-742.

Börsch-Supan, A., Hajivassiliou, V., Kotlikoff, L., Morris, L., 1992. Health, children, and elderly living arrangements: A multiperiod-multinomial probit model with unobserved heterogeneity and autocorrelated errors, in: Wise, D. (Ed.), Topics in the Economics of Aging. Chicago: The University of Chicago Press, pp. 79104.

Börsch-Supan, A., Hajivassiliou, V., 1993. Smooth unbiased multivariate probability simulators for maximum likelihood estimation of limited dependent variable models. Journal of Econometrics 58, 347-368.

Boyer, C. N., Adams, D. C., Borisova, T., Clark, C. D., 2012. Factors driving water utility rate structure choice: evidence from four southern US states. Water Resources Management, 26(10), 2747-2760.

Bucciol, A., Cavalli, L., Pertile, P., Polin, V., Sommacal, A., 2013. Redistribution at the local level: the case of public childcare in Italy. Working Papers 21/2013, University of Verona, Department of Economics.

Cameron, A. C., Trivedi, P. K., 2009. Microeconometrics using stata. College Station, Texas: Stata Press.

Cappellari, L. Jenkins, S. P., 2003. Multivariate Probit Regression Using Simulated Maximum Likelihood. The Stata Journal 3(3), 278-294.

Chernick, H., 1992. A model of the distributional incidence of state and local taxes. Public Finance Quarterly 20 (4), 572-85. DOI: 10.1177/109114219202000412. 
Chernick, H., 2005. On the determinants of subnational tax progressivity in the US. National Tax Journal, 93-112.

Chong, E., Huet, F., Saussier, S., Steiner, F., 2006. Public-private partnerships and prices: evidence from water distribution in France. Review of Industrial Organization 29 (1/2), 149-169.

Dandy, G., Nguyen, T., Davies, C., 1997. Estimating residential water demand in the presence of free allowances. Land Economics 73, 125-39.

Egger, P., Radulescu, D., Rees, R., 2014. The determinants of personal income tax progressivity around the globe. Unpublished paper. Available at:

http://www.sv.uio.no/econ/english/research/news-and-events/events/guestlectures-seminars/ofs-seminar/documents/Radulescu.pdf

FACUA, 2013. Estudio comparativo sobre las tarifas del agua en 28 ciudades. Sevilla, Spain.

Fletcher, J. M., Murray, M. N., 2008. What factors influence the structure of the state income tax?. Public Finance Review 36(4), 475-496.

DOI: $10.1177 / 1091142107303720$

Foster, J. M., 2013. Voter ideology, economic factors, and state and local tax progressivity. Public Finance Review 41(2), 177-202.

García-Valiñas, M.A., 2005. Efficiency and equity in natural resources pricing: a proposal for urban water distribution service. Environmental and Resource Economics 32(2), 183-204.

García-Valiñas, M.A., Martínez-Espiñeira, R., González-Gómez, F., 2010. Affordability of residential water tariffs: alternative measurement and explanatory factors in southern Spain. Journal of Environmental Management 91(12), 2696-2706.

García-Valiñas, M. A., González-Gómez, F., Picazo-Tadeo, A.J., 2013. Is the price of water for residential use related to provider ownership? Empirical evidence from Spain. Utilities Policy 24, 59-69.

Greene, W. H., 2003. Econometric Analysis. 5th Ed. Prentice Hall, New York

Hajivassiliou, V., Ruud. P., 1994. Classical estimation methods for LDV models using simulation, in: Engle, R., McFadden, D. (Eds), Handbook of Econometrics vol. IV. Amsterdam: North-Holland, pp. 2383-2441.

Hernández-Sacho, F., Molinos-Senante, M., 2015. Water consumption, tariffs and regulation. IWA Publishing. London, UK.

Hoque, S. F., Wichelns, D., 2013. State-of-the-art review: designing urban water tariffs to recover costs and promote wise use. International Journal of Water Resources Development 29(3), 472-491. 


$$
\text { (2014). }
$$

Padrón

municipal.

Madrid.

Available

at:

http://www.ine.es/jaxi/menu.do?type=pcaxis\&path=\%2Ft20\%2Fe260\&file=ineba se $\& L=0$

Jacobs, J.W., Howe, C.W., 2005. Key issues and experience in US water services privatization. International Journal of Water Resources Development 21(1), 8998.

Kakwani, N.C., 1977. Measurement of tax progressivity: an international comparison. The Economic Journal 87, 71-80.

Keane, M. P. A., 1994. Computationally Practical Simulation Estimator for Panel Data. Econometrica 62(1), 95-116 .

Madhoo, Y.N., 2009. Policy and nonpolicy determinants of progressivity of block residential water rates - a case study of Mauritius. Applied Economics Letters 16(2), 211-215.

Martínez-Espiñeira, R., 2002. Residential Water Demand in the Northwest of Spain. Environmental and Resource Economics 21,161-187.

Martínez-Espiñeira, R., García-Valiñas, M.A., González-Gómez, F., 2012. Is the pricing of urban water services justifiably perceived as unequal among Spanish cities?. International Journal of Water Resources Development 28(1), 107-121.

Martins, R., Cruz, L., Barata, E., Quintal, C., 2013. Assessing social concerns in water tariffs. Water Policy 15(2), 193-211.

Massarutto, A., 2007. Water pricing and full cost recovery of water services: economic incentive or instrument of public finance?. Water Policy 9(6), 591-613.

Musgrave, R.A., Thin, T., 1948. Income tax progression, 1929-48. Journal of Political Economy 56, 498-514.

OCU, 2014. Precio del agua. OCU, Compra Maestra 390, 23-25.

OECD 2003. Social issues in the provision and pricing of water services. OECD Publishing, Paris, France.

OECD 2010. Pricing water resources and water and sanitation services. OECD Publishing, Paris, France.

Orr, L., 1976. Income transfers as a public good: an application to AFDC. American Economic Review 66(3), 359-71.

Padovano, F., Turati, G., 2012. Redistribution through a "leaky bucket". What explains the leakages?. Economics working paper from Condorcet Center for Political Economy at CREM-CNRS, Condorcet Center for Political Economy. 
Rogers, P., de Silva, R., Bhatia, R., 2002. Water is an economic good: how to use prices to promote equity, efficiency, and sustainability. Water Policy 4, 1-17.

Roodman, D., 2011. Fitting fully observed recursive mixed-process models with $\mathrm{cmp}$. The Stata Journal 11, 159-206

Ruester, S., Zschille, M., 2010. The impact of governance structure on firm performance: an application to the German water distribution sector. Utilities Policy 18 (3), 154-162.

Seidl, C., Pogorelskiy, K., Traub, S., 2013. Tax progression in OECD countries: An Integrative Analysis of Tax Schedules and Income Distributions. SpringerVerlag Berlin Heidelberg

Solé-Ollé, A., 2003. Electoral accountability and tax mimicking: the effects of electoral margins, coalition government, and ideology. European Journal of Political Economy 19(4), 685-713.

Statacorp, 2011. Stata Statistical Software: Release 12 StataCorp LP. College Station, $\mathrm{TX}$

Train, K. E., 2003. Discrete Choice Methods with Simulation. Cambridge University Press, Cambridge.

UN Water 2013. Water security and the global water agenda. A UN-Water Analytical Brief. Hamilton (Ontario), Canada.

UN Water 2014. Securing sustainable water for all. A Post---2015 Global Goal for Water: Synthesis of key findings and recommendations from UN---Water.

Worthington, A.C., Hoffman,M., 2008. An empirical survey of residential water demand modelling. Journal of Economic Surveys 22(5), 842-871. 
APPENDIX

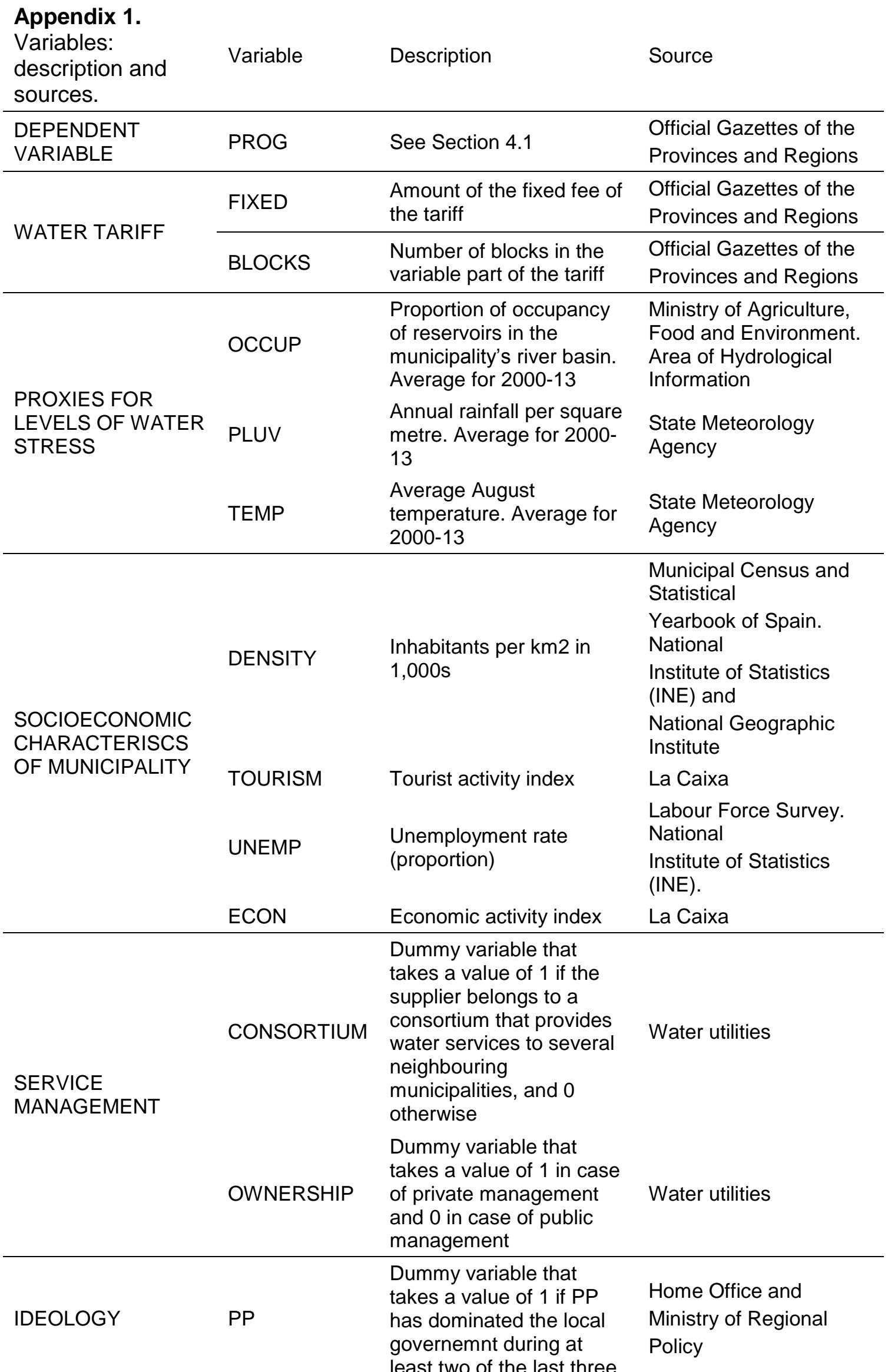




\begin{tabular}{|c|c|c|c|}
\hline & & $\begin{array}{l}\text { 4-year ruling periods, and } \\
0 \text { en otherwise }\end{array}$ & \\
\hline & PSOE & $\begin{array}{l}\text { Dummy variable that } \\
\text { takes a value of } 1 \text { if } \\
\text { PSOE has dominated the } \\
\text { local governemnt during } \\
\text { at least two of the last } \\
\text { three } 4 \text {-year ruling } \\
\text { periods, and } 0 \text { en } \\
\text { otherwise }\end{array}$ & $\begin{array}{l}\text { Home Office and } \\
\text { Ministry of Regional } \\
\text { Policy }\end{array}$ \\
\hline & IU & $\begin{array}{l}\text { Dummy variable that } \\
\text { takes a value of } 1 \text { if IU } \\
\text { has dominated the local } \\
\text { governemnt during at } \\
\text { least two of the last three } \\
4 \text {-year ruling periods, and } \\
0 \text { en otherwise }\end{array}$ & $\begin{array}{l}\text { Home Office and } \\
\text { Ministry of Regional } \\
\text { Policy }\end{array}$ \\
\hline & LEFT & $\begin{array}{l}\text { Dummy variable that } \\
\text { takes a value of } 1 \text { if left- } \\
\text { wing regional parties } \\
\text { have dominated the local } \\
\text { governemnt during at } \\
\text { least two of the last three } \\
4 \text {-year ruling periods, and } \\
0 \text { en otherwise }\end{array}$ & $\begin{array}{l}\text { Home Office and } \\
\text { Ministry of Regional } \\
\text { Policy }\end{array}$ \\
\hline & RIGHT & $\begin{array}{l}\text { Dummy variable that } \\
\text { takes a value of } 1 \text { if right- } \\
\text { wing regional parties } \\
\text { have dominated the local } \\
\text { governemnt during at } \\
\text { least two of the last three } \\
4 \text {-year ruling periods, and } \\
0 \text { otherwise }\end{array}$ & $\begin{array}{l}\text { Home Office and } \\
\text { Ministry of Regional } \\
\text { Policy }\end{array}$ \\
\hline & STAB & $\begin{array}{l}\text { Dummy variable: equal to } \\
1 \text { if the same party ruled } \\
\text { during the last two ruling } \\
\text { periods in a row, } 0 \\
\text { otherwise. }\end{array}$ & $\begin{array}{l}\text { Home Office and } \\
\text { Ministry of Regional } \\
\text { Policy }\end{array}$ \\
\hline POLICY & MAJOR & $\begin{array}{l}\text { Dummy variable: equals } \\
1 \text { if during the last three } \\
\text { ruling periods the most } \\
\text { voted party secured over } \\
50 \% \text { of votes; } 0 \text { otherwise }\end{array}$ & $\begin{array}{l}\text { Home Office and } \\
\text { Ministry of Regional } \\
\text { Policy }\end{array}$ \\
\hline & CCAAi & $\begin{array}{l}\text { Dummy for each } \\
\text { autonomous community } \\
(\mathrm{i}=1 \ldots 18)\end{array}$ & $\begin{array}{l}\text { National } \\
\text { Institute of Statistics } \\
\text { (INE) }\end{array}$ \\
\hline
\end{tabular}




\section{TABLES}

Table 1: Comparison of the distribution of municipalities by size (census population) in the sample versus the population

\begin{tabular}{lrrrr}
\hline & Population & \multicolumn{3}{c}{ Sample } \\
\cline { 2 - 5 } & 1193 & 14.70 & 37 & 3.83 \\
\hline Municipalities & Percentage & Municipalities & Percentage \\
from 101 to 500 & 2670 & 32.89 & 128 & 13.24 \\
from 501 to 1,000 & 1033 & 12.73 & 78 & 8.07 \\
from 1,001 to 2,000 & 912 & 11.24 & 95 & 9.82 \\
from 2,001 to 3,000 & 501 & 6.17 & 74 & 7.65 \\
from 3,001 to 5,000 & 490 & 6.04 & 86 & 8.89 \\
from 5,001 to 10,000 & 560 & 6.90 & 141 & 14.58 \\
from 10,001 to 20,000 & 355 & 4.37 & 126 & 13.03 \\
from 20,001 a 30,000 & 154 & 1.90 & 67 & 6.93 \\
From 30,001 to 50,000 & 103 & 1.27 & 45 & 4.65 \\
From 50,001 to 100,000 & 83 & 1.02 & 47 & 4.86 \\
From 100,001 to 500,000 & 57 & 0.70 & 39 & 4.03 \\
Over 500,000 & 6 & 0.07 & 4 & 0.41 \\
\hline TOTAL & 8117 & 100.00 & 967 & 100.00 \\
\hline
\end{tabular}

Source: INE (2014) and own construction using fieldwork data 
Table 2. Descriptive statistics

\begin{tabular}{lrrrr}
\hline Variable & Mean & Std. Dev. & Min & Max \\
\hline DENSITY & 0.643 & 1.896 & 0.00105 & 24.550 \\
OCCUP & 69.321 & 17.110 & 0 & 90.359 \\
PLUV & 639.898 & 249.531 & 279.934 & 1511.846 \\
TEMP & 22.910 & 2.474 & 17.94 & 26.393 \\
CONSORTIUM & 0.345 & 0.476 & 0 & 1 \\
PRIVATE & 0.388 & 0.488 & 0 & 1 \\
TOURISM & 0.399 & 3.393 & 0 & 94 \\
UNEMP & 0.109 & 0.073 & 0 & 0.283 \\
ECON & 0.524 & 3.633 & 0 & 104.88 \\
STAB & 0.764 & 0.425 & 0 & 1 \\
MAJOR & 0.346 & 0.476 & 0 & 1 \\
PP & 0.356 & 0.479 & 0 & 1 \\
PSOE & 0.311 & 0.463 & 0 & 1 \\
IU & 0.024 & 0.152 & 0 & 1 \\
FIXED & 3.709 & 2.171 & 0 & 17.5 \\
BLOCKS & 2.954 & 1.229 & 1 & 7 \\
CCAA1 & 0.001 & 0.032 & 0 & 1 \\
CCAA2 & 0.178 & 0.383 & 0 & 1 \\
CCAA3 & 0.042 & 0.202 & 0 & 1 \\
CCAA4 & 0.020 & 0.139 & 0 & 1 \\
CCAA5 & 0.004 & 0.064 & 0 & 1 \\
CCAA6 & 0.032 & 0.176 & 0 & 1 \\
CCAA7 & 0.027 & 0.162 & 0 & 1 \\
CCAA8 & 0.021 & 0.142 & 0 & 1 \\
CCAA9 & 0.024 & 0.152 & 0 & 1 \\
CCAA10 & 0.067 & 0.251 & 0 & 1 \\
CCAA11 & 0.077 & 0.266 & 0 & 1 \\
CCAA12 & 0.022 & 0.146 & 0 & 1 \\
CCAA13 & 0.030 & 0.171 & 0 & 1 \\
CCAA14 & 0.026 & 0.159 & 0 & 1 \\
CCAA15 & 0.112 & 0.315 & 0 & 1 \\
CCAA16 & 0.021 & 0.142 & 0 & 1 \\
CCAA17 & 0.132 & 0.339 & 0 & 1 \\
LEFT & 0.022 & 0.146 & 0 & 1 \\
RIGHT & 0.063 & 0.243 & 0 & 1 \\
\hline & & & & \\
& 0.37 \\
\hline
\end{tabular}


Table3. Tariff descriptive statistics

\begin{tabular}{lrrrrr}
\hline Variable & $N$ & Mean & Std. Dev. & Min & Max \\
\hline Fixed $(€)$ & 967 & 3.709 & 2.171 & 0.000 & 17.500 \\
Blocks & 967 & 2.954 & 1.229 & 1.000 & 7.000 \\
bill $(€)$ & 967 & 1.081 & 0.789 & 0.000 & 8.280 \\
bill $_{5}(€)$ & 967 & 1.843 & 1.245 & 0.000 & 7.500 \\
bill $_{10}(€)$ & 967 & 4.350 & 2.667 & 0.000 & 20.000 \\
bill $_{15}(€)$ & 967 & 7.893 & 4.507 & 0.000 & 32.500 \\
bill $_{20}(€)$ & 967 & 12.273 & 7.166 & 0.000 & 45.000 \\
bill $_{25}(€)$ & 967 & 17.462 & 10.585 & 0.950 & 60.895 \\
bill $_{50}(€)$ & 967 & 48.901 & 30.409 & 4.500 & 180.142 \\
\hline
\end{tabular}


Table 4. CMP and OLS regression results

\begin{tabular}{|c|c|c|c|c|c|c|}
\hline \multirow{2}{*}{ Variable } & \multicolumn{3}{|c|}{ OLS } & \multicolumn{3}{|c|}{ CMP } \\
\hline & PROG & BLOCKS & FIXED & PROG & BLOCKS & FIXED \\
\hline DENSITY & $-0.027^{*}$ & 0.003 & -0.02 & $-0.026 * *$ & 0.003 & -0.02 \\
\hline OCCUP & -0.001 & 0.027 & 0.013 & -0.001 & 0.027 & 0.013 \\
\hline PLUV & $-0.002 * * *$ & $-0.002 *$ & $-0.004 * *$ & $-0.001 * * *$ & $-0.002 * *$ & $-0.004 * * *$ \\
\hline TEMP & -0.046 & $-0.296 * *$ & -0.062 & -0.064 & $-0.296 * *$ & -0.062 \\
\hline CONSORTIUM & $0.176^{* *}$ & 0.077 & -0.832 & $0.249 * * *$ & 0.077 & -0.832 \\
\hline PRIVATE & -0.109 & $0.759 * * *$ & -0.478 & -0.011 & $0.759 * * *$ & -0.478 \\
\hline TOURISM & $0.016 * *$ & -0.048 & $0.080 * *$ & 0.005 & -0.048 & $0.080 * * *$ \\
\hline UNEMP & 0.513 & $2.953^{*}$ & 2.033 & 0.576 & $2.953^{* *}$ & 2.033 \\
\hline ECON & $-0.014^{*}$ & 0.044 & $-0.069 * *$ & -0.005 & 0.044 & $-0.069 * *$ \\
\hline STAB & $-0.263 * *$ & 0.409 & 0.024 & $-0.234 *$ & 0.409 & 0.024 \\
\hline MAJOR & 0.044 & 0.034 & -0.345 & 0.075 & 0.034 & -0.345 \\
\hline PP & $0.180^{* *}$ & -0.357 & 0.461 & 0.115 & -0.357 & 0.461 \\
\hline PSOE & 0.177 & -0.359 & 0.251 & 0.129 & -0.359 & 0.251 \\
\hline IU & 0.034 & 0.449 & -0.398 & 0.101 & 0.449 & -0.398 \\
\hline FIXED & $0.083^{* * *}$ & & & $0.164 * * *$ & & \\
\hline BLOCKS & $0.128 *$ & & & 0.051 & & \\
\hline CCAA1 & 0.079 & -0.285 & -2.531 & 0.263 & -0.285 & -2.531 \\
\hline CCAA2 & $0.281 * * *$ & $0.669 *$ & -0.759 & $0.395^{* * *}$ & 0.669* & $-0.759 *$ \\
\hline CCAA3 & 0.113 & 0.006 & -1.866 & 0.266 & 0.006 & -1.866 \\
\hline CCAA4 & $1.486^{* * *}$ & 0.185 & 0.667 & $1.446 * * *$ & 0.185 & 0.667 \\
\hline CCAA5 & 0.167 & 1.425 & -0.562 & 0.323 & 1.425 & -0.562 \\
\hline CCAA6 & $0.966 * *$ & -0.939 & 0.764 & 0.831 & -0.939 & 0.764 \\
\hline CCAA7 & -0.249 & $1.686^{* *}$ & 1.646 & -0.252 & $1.686^{* *}$ & 1.646 \\
\hline CCAA8 & $1.328^{* * *}$ & -0.051 & 1.851 & $1.173^{* *}$ & -0.051 & 1.851 \\
\hline CCAA9 & $0.285^{*}$ & $1.151^{* *}$ & -1.034 & $0.458 * *$ & $1.151^{* *}$ & -1.034 \\
\hline CCAA10 & 0.188 & -0.737 & -2.168 & 0.308 & -0.737 & -2.168 \\
\hline CCAA11 & $0.366 * *$ & 0.998* & 0.466 & $0.405^{* *}$ & 0.998* & 0.466 \\
\hline CCAA12 & $-0.234^{* *}$ & $0.910 * *$ & $-1.754 * * *$ & -0.021 & $0.910 * *$ & $-1.754 * * *$ \\
\hline CCAA13 & $1.512^{* * *}$ & 0.719 & 4.312 & $1.216^{* *}$ & 0.719 & 4.312 \\
\hline CCAA14 & $-0.326 * *$ & -0.234 & -2.159 & -0.169 & -0.234 & -2.159 \\
\hline CCAA15 & $0.267 * * *$ & 0.36 & $3.619 * * *$ & 0.000 & 0.36 & $3.619 * * *$ \\
\hline CCAA16 & $-0.794 * * *$ & $1.242 * * *$ & $2.665 * * *$ & $-0.915 * * *$ & $1.242^{* * *}$ & $2.665^{* * *}$ \\
\hline CCAA17 & $-0.426^{*}$ & $-2.500 * *$ & -1.324 & -0.512 & $-2.500 * * *$ & -1.324 \\
\hline LEFT & $0.441 *$ & $-0.786 * *$ & -0.311 & 0.406 & $-0.786 * * *$ & -0.311 \\
\hline RIGHT & 0.072 & 0.024 & $1.356^{* *}$ & -0.037 & 0.024 & $1.356^{* *}$ \\
\hline constant & $2.149 *$ & $8.633^{* *}$ & 6.736 & $2.269 *$ & $8.633^{* * *}$ & $6.736 *$ \\
\hline$\rho_{12}$ & & & & & & $0.188^{* * *}$ \\
\hline$\rho_{13}$ & & & & & & $-0.311 * * *$ \\
\hline$\rho_{23}$ & & & & & & -0.076 \\
\hline \multicolumn{7}{|l|}{ Statistics } \\
\hline $\mathrm{N}$ & 967 & 967 & 967 & & & 967 \\
\hline R2 & 0.528 & 0.506 & 0.674 & & & \\
\hline log-likelihood & -282.92 & -1082 & -1603.4 & & & -3583.5 \\
\hline
\end{tabular}

